\title{
Cryogenic Storage of Tomato Pollen: Effect on Fecundity
}

\author{
Erik J. Sacks and Dina A. St. Clair \\ Department of Vegetable Crops, University of California, Davis, CA 95616
}

Additional index words. Lycopersicon esculentum, pollen storage, low temperature, germplasm conservation, seed number

\begin{abstract}
The influence of cryogenic pollen storage on fruit set and seed production in tomato (Lycopersicon esculentum Mill.) was investigated. Flowers pollinated with pollen samples stored for 5 weeks at $-80 \mathrm{C}$, with or without $20 \mathrm{~h}$ precooling at $4 \mathrm{C}$, had similar fruit set and number of viable seed per fruit as those pollinated with fresh pollen. Pollen samples, which were repeatedly cooled (-80C) and warmed (to 22 to $24 \mathrm{C}$ ) for up to six cycles, continuously maintained the same viability as the fresh pollen. When cryogenically stored pollen of L. esculentum 2-837, LA359, LA3198, and LA3199 were used to pollinate LA359, the number of viable seed formed per fruit differed significantly. Results of this study suggest that pollen cryopreservation can be used successfully for tomato breeding and germplasm storage.
\end{abstract}

The ability to store viable pollen for long periods enables breeders to cross-pollinate plants grown at different times or locations and to conserve germplasm in a minimum of space. Successful cryopreservation of pollen has been reported for a diverse group of species, including Clianthus formosus (G. Don) Ford and Vickery (Hughes et al., 1991), Juglans regia L. (Luza and Polito, 1988), Panax ginseng L. (Zhang et al., 1993), and Solanum tuberosum L. (Weatherhead etal., 1978). Visser (1955) successfully germinated tomato pollen stored at $-190 \mathrm{C}$ for 2 years and $-20 \mathrm{C}$ for 3 years. With pollen from the latter treatment Visser (1955) obtained two fruit with seed. In contrast, McGuire (1952) found that tomato pollen stored at $0 \mathrm{C}$ was nonfunctional after 6 months of storage. The objectives of our research were to 1) quantify the effect of $-80 \mathrm{C}$ pollen storage on seed production; 2) determine if desiccation of pollen at $4 \mathrm{C}$ before $-80 \mathrm{C}$ storage would be beneficial; and 3) determine if a stored pollen supply could be repeatedly brought to a greenhouse for pollinations and returned to $-80 \mathrm{C}$ without decreasing seed production.

\section{Materials and Methods}

Seed stocks of $L$. esculentum accessions 2837 ( $m s-15^{47}$ in 'UC82B'), LA359 ( $m s-32$ in var. cerasiforme), LA3198 ( $M s$-48 in 'T5'), and LA3199 (Ms-48 in 'VFNT Cherry') were obtained from the Tomato Genetics Resource Center (Rick and Chetelat, 1993). Each stock segregated 1:1 for male sterility and male fertility (Roger Chetelat, personal communication). Male-fertile plants (+/ms for recessives or $+/+$ for $M s-48$ ) from each accession were used as sources of pollen. Seeds were

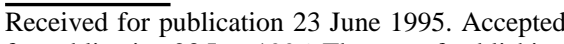
for publication 23 Jan. 1996. The cost of publishing this paper was defrayed in part by the payment of page charges. Under postal regulations, this paper therefore must be hereby marked advertisement solely to indicate this fact. sown in flats containing Supersoil (Rod McLellan Co., South San Francisco) on 7 Dec. 1993 and grown in a fiberglass greenhouse at Davis, Calif. Plants were transferred, 4 to 6 weeks after sowing, to 8-liter pots containing a 2 sphagnum moss : 1 perlite: 1 vermiculite (by volume) mixture. To minimize environmental effects, 17 male-sterile plants of LA359 that served as females were placed in two rows on a single bench, located away from the cooling pads. For the duration of the experiment, high and low temperatures and relative humidities ( $\mathrm{RH})$ were 30 to $12 \mathrm{C}$ and $100 \%$ to $23 \%$, respectively.

On 21 Mar. 1994, pollen was collected from seven, two, four, and two plants of 2-837, LA359, LA3198, and LA3199, respectively. Pollen was collected directly into open No. 0 gelatin capsules (Eli Lilly and Co., Indianapolis) with the aid of an electric toothbrush modified to permit vibration of the tomato flower anther cone. For a given genotype, pollen from several individuals was mixed together and aliquots were placed in gelatin capsules. Each capsule was wrapped in tissue paper and placed in a 12-ml glass screw-cap vial half-filled with $\mathrm{CaSO}_{4}$ indicating desiccant (W.A. Hammond Drierite Co., Xenia, Ohio). Vials were placed in polypropylene storage boxes (1.2-liter capacity) containing fiberboard cell dividers (PGC Scientific, Gaithersburg, Md.) and $\approx 250 \mathrm{ml}$ of desiccant. All storage treatments commenced within $2 \mathrm{~h}$ of pollen collection.

Freezing once (Expt. 1). Pollen of LA359 and LA3198 collected on 21 Mar. was stored at $-80 \mathrm{C}$ within $15 \mathrm{~min}$ of the capsule being contained in a vial (designated as treatment ASAPfrz). Aliquots of the same pollen were stored at $4 \mathrm{C}$ within $15 \mathrm{~min}$ of the capsule being placed in a vial with desiccant, then transferred to $-80 \mathrm{C}$ after $\approx 20 \mathrm{~h}$ (designated as treatment DESCfrz). As a control treatment, fresh pollen was used to pollinate flowers within $2 \mathrm{~h}$ of collection.

Cycles of warming and cooling (Expt. 2). Pollen of 2-837 and LA3199 was given 0 to 6 cycles of warming and recooling. Cycle 0 pollen was treated the same as the DESCfrz pollen of Expt. 1. A single cycle was initiated by removing the vial from the $-80 \mathrm{C}$ freezer at $\approx 8: 00 \mathrm{AM}$, transporting the vial to the greenhouse, and removing the enclosed capsule of pollen after the vial had reached room temperature. Capsules were enclosed in brown paper bags that were placed on a greenhouse bench and covered by large overturned pots to provide additional shade. A cycle was concluded by returning the capsule to the vial at about noon, storing the vial at $4 \mathrm{C}$ for $\approx 20 \mathrm{~h}$, then transferring it to $-80 \mathrm{C}$. Because gelatin capsules are permeable to air and water, pollen was assumed to have been exposed to temperatures from 22 to $24 \mathrm{C}$ and $30 \%$ to $69 \% \mathrm{RH}$ while in the greenhouse. The amount of time elapsed between the initiation of consecutive cycles was 2 days. Cycle 1 was initiated on 23 Mar. and cycle 6 was concluded on 3 Apr.

Pollination procedures. Pollinations for Expts. 1 and 2 were made on 27 and 28 Apr. 1994, respectively. On each day of pollinations, the available flowers were considered a population to which pollen treatments and genotypes were randomly assigned. All flowers on a plant (4 to 23 ) were pollinated before a new plant was used. The experiments were not designed to block by plant because on a given day each female plant produced an unpredictable number of flowers. Six and 10 plants of LA359 were used as females in Expts. 1 and 2, respectively. For each combination of pollen treatment and genotype, 10 open but unfaded flowers (up to three per inflorescence) were pollinated. The temperature and relative humidity for the two pollination dates ranged from 16 to $21 \mathrm{C}$ and $64 \%$ to $90 \%$ and 15 to $22 \mathrm{C}$ and $62 \%$ to $97 \%$, respectively. No special effort was made to rehydrate the pollen before pollination. Stigmas were thoroughly coated with pollen.

Seed germination. The time from fruit harvest to commencement of the seed germination test was $\approx 2$ and 8 months for Expt. 1 and Expt. 2, respectively. Seed from each fruit was germinated separately. Random samples of 30 seeds per fruit were placed in separate 15-ml, sterile, centrifuge tubes (Corning, Corning, N.Y.). Seeds were surface-sterilized with $0.525 \%$ sodium hypochlorite for $10 \mathrm{~min}$ and rinsed three times with sterile aqueous $0.2 \%$ $\mathrm{KNO}_{3}$ solution. The tubes were then filled to $\approx 8 \mathrm{ml}$ with the $\mathrm{KNO}_{3}$ solution, and each tube was emptied into a sterile $100 \times 25$-mm petri dish containing autoclaved steel blue seedgermination blotter paper (Anchor Paper Co., St. Paul, Minn.). Petri dishes containing seeds were maintained for 14 days at $25 \mathrm{C}$ under fluorescent light (55 to $140 \mu \mathrm{mol} \cdot \mathrm{m}^{-2} \cdot \mathrm{s}^{-1}$ ) for $16 \mathrm{~h} \cdot$ day $^{-1}$. The number of viable seed per fruit was estimated by multiplying the number of seed in each fruit by the average percentage (99\%) of seeds that germinated in each experiment.

Statistical analysis. Both experiments were completely randomized designs. For all analyses, the dependent variable was the number of viable seed per fruit. For Expt. 1, an analysis of variance was conducted using the SAS (1988) 
GLM procedure with Type III sums of squares to test for main effects of male, treatment, and male $\times$ treatment interactions. For Expt. 2, an analysis of covariance (ANCOVA) tested the main effects of male genotype (BMDP, 1992). The covariate was the number of cycles of warming and cooling.

\section{Results and Discussion}

All but one of the pollinated flowers set and six fruit were unintentionally pruned off. No unpollinated flowers set fruit. Within each experiment, seed germination for each combination of pollen treatment and genotype ranged from $98 \%$ to $100 \%$.

The number of viable seed in both experiments varied considerably within genotype and treatment. Within genotype and treatment, standard deviations ranged from 26 to 54 seed per fruit. These results are consistent with observations on potato (Howard, 1958). Means for Expt. 1 ranged from 126 seed per fruit for fresh LA3198 pollen to 170 for DESCfrz LA359 pollen. No significant interactions or main effects were found in Expt. 1, suggesting that pollen can be stored successfully at $-80 \mathrm{C}$ shortly after it is collected and without artificial desiccation.
Means for Expt. 2 ranged from 123 to 150 seed per fruit for cycle 0 pollen of LA3199 and 2-837, respectively. For Expt. 2, the ANCOVA did not detect significant differences between 2-837 and LA3199 for number of viable seeds per fruit. The regression coefficients for 2-837 and LA3199 were homogeneous. There was a loss of 0.5 seeds per cycle, but this slope was not significantly different from zero. Thus, a pollen source can be sampled and restored repeatedly at $-80 \mathrm{C}$ for $\approx 1$ month without a decrease in the number of viable seeds per pollination.

Cryopreservation of tomato pollen can be a useful tool for germplasm conservation and plant improvement. Germplasm collectors can sample natural populations by harvesting pollen from plants that are blooming but lack ripe fruit or seed. Germplasm banks can decrease the demand for seed of their tomato stocks by offering researchers pollen.

Successful cryogenic storage of pollen from S. tuberosum (Weatherhead et al., 1978), a distant relative of tomato, suggests that species more closely related to $L$. esculentum also may be amenable to cryopreservation. We have successfully stored pollen of $L$. hirsutum Humb. and Bonpl. and L. peruvianum Mill. at $-80 \mathrm{C}$ for $\approx 10$ months (unpublished). Thus,
$-80 \mathrm{C}$ pollen storage likely is feasible for all the species of Lycopersicon.

\section{Literature Cited}

BMDP. 1992. BMDP statistical software manual. Univ. of California Press, Berkeley.

Howard, H.W. 1958. The storage of potato pollen. Amer. Potato J. 35:676-678.

Hughes, H.G., C.W. Lee, and L.E. Towill. 1991. Low-temperature preservation of Clianthus formosus pollen. HortScience 26:1411-1412.

Luza, J.G. and V.S. Polito. 1988. Cryopreservation of English walnut (Juglans regia L.) pollen. Euphytica 37:141-148.

McGuire, D.C. 1952. Storage of tomato pollen. Proc. Amer. Soc. Hort. Sci. 60:419-424.

Rick, C.M. and R.T. Chetelat. 1993. TGRC stock lists. Rpt. Tomato Genet. Coop. 43:53-78.

SAS Institute. 1988. SAS/STAT users guide, release 6.03. SAS Inst., Cary, N.C.

Visser, T. 1955. Germination and storage of pollen. Meded. Landbouwhogesch. Wageningen 55:168.

Weatherhead, M.A., B.W.W. Grout, and G.G. Henshaw. 1978. Advantages of storage of potato pollen in liquid nitrogen. Potato Res. 21:331334.

Zhang, L.X., W.C. Chang, Y.J. Wei, L. Liu, and Y.P. Wang. 1993. Cryopreservation of ginseng pollen. HortScience 28:742-743. 